\title{
Nanotechnological innovation for the production of daughter less Tilapia, Oreochromis niloticus (Linnaeus, 1758)
}

\author{
${ }^{1 *}$ Harshavardhan D. Joshi, ${ }^{1}$ V. K. Tiwari, ${ }^{2}$ Rupam Sharma, ${ }^{3}$ Subodh Gupta, ${ }^{2}$ W. S. Lakra \\ and ${ }^{1}$ Upasana Sahoo
}

${ }^{1}$ Aquaculture Division, Central Institute of Fisheries Education, Andheri (W), Mumbai-400061(Maharashtra), INDIA

${ }^{2}$ Fisheries Genetics \& Biotechnology, Division, Central Institute of Fisheries Education, Andheri (W), Mumbai400061(Maharashtra), INDIA

${ }^{3}$ Fish Nutrition, Biochemistry and Physiology Division, Central Institute of Fisheries Education, Andheri (W), Mumbai-400061 (Maharashtra), INDIA

*Corresponding author E-mail: harshjoshicofsn@gmail.com

Received: November 18, 2016; Revised received: April 30, 2017; Accepted: September 10, 2017

Abstract: The aim of present work was to develop a new Fadrozole (FDZ)-loaded Poly(D,L-lactide-co- glycolide) lactide:glycolide (50:50)(PLGA) nanoparticles for effective delivery of the masculinization drug, Fadrozole, as an alternative to commercially available masculinization agents like testosterone (dietary supplementation of $17 \mathrm{a}$ methyltestosterone) which are steroids and banned in most EU countries. The FDZ-loaded PLGA NPs were prepared by solvent displacement technique. The particle size of FDZ-loaded PLGA NPs was analyzed using LICOMP particle size analyser. It was found to be in the range of $60 \pm 66.7 \mathrm{~nm}$ to $560 \pm 66.7 \mathrm{~nm}$ with average size of 201.4 $\pm 66.7 \mathrm{~nm}$, where the Zeta potential was estimated to be about $-20.82 \mathrm{mV}$, a series of experiments were carried out to induce masculinization using FDZ-loaded PLGA nanoparticles during the sex differentiation period. Tilapia, Oreochromis niloticus fry were treated with FTZ-loaded PLGA nanoparticles at dosages 5, 25, 50 and 100ppm/kg diet for 10, 15 and 30 days. The results indicated an increase in the proportion of males with dosage and duration of treatment. The male percentage was $92.35 \pm 0.86$ for $\mathrm{T} 7(50 \mathrm{ppm})$ at 10 days, $97.76 \pm 1.12$ for T7 (100 ppm) at 15 days and $100 \%$ for both T6 (50ppm) and T7 (100 ppm) at 30 days. This is first time done by using nanotechnology efficiently in Tilapia species which is very important Fresh water aquaculture species in present era. Which showed increase the male population with lesser dose of nano-encapsulated Fadrozole (FDZ)-loaded PLGA nanoparticles drug as compared with naked control Fadrozole (FDZ) drug delivery.

Keywords: Bio-dégradable, Fadrozole, Masculinisation, Nanoparticle, PLGA, Oreochromis niloticus

\section{INTRODUCTION}

Tilapia has been exacting as the Food Fish of the 21 st century and is widely known as "Aquatic chicken" (Khawa et al., 2003). The culture of only male tilapia or hybrid is only allowed in India so as to evade / detention productive breeding during culture period (NABARD, 2016).

Nanoparticles (NPs) are believed to be the best drug delivery system, have substantial potential for drug directing means target drug delivery and show numerous benefits over conformist delivery systems like low drug requirement, specificity, target drug delivery etc. (Otilia et al., 2005, Hughes, G.A., 2005). Drugs conjugated with nanoparticles can be targeted to a specific site of action with accompaniment decrease in the extent of drug necessary and amount venomousness means toxicity, permitting safe delivery of deadly therapeutic drugs as well as defence of non-goal matters and cells from unadorned side effects and indemnities (Brannon-Peppas, L., 1995). Since the application of nanoparticle is always associated with the concern of its ill effect, recyclable polymeric nanoparticles obligate anew been the choice of the researchers. These polymers have already been used as carriers for anticancer agents (Brigger et. al., 2002), (Vauthier et. al., 2003) With this background, the present research work has been designed to develop PLGA loaded fadrozole nanoparticles for producing all male population of tilapia Oreochromis niloticus.

Only in the later half of the 20th century, use of gonadal hormones in the manipulation of sex was initiated and the initial studies were mainly carried out on fishes having little or no commercial significance. In fish, two aromatase iso-forms have been designated, one specially articulated in the ovary (implicit by the CYP19a gene) and one specially expressed in the brain (coded by the CYP19b gene) (Chiang et. al., 2001). Tchoudakova et. al., (2011) stated that the gonads, aromatase takes revealed to be a key enzyme adaptable sexual diversity in fish. During early progress, obstructive aromatase will distinguish the gonads into testis 
(Komatsu et. al., 2006), while estrogen administration will cause the development of ovaries (Piferrer, F., 2001). In the recent past decade the Fadrozole a nonsteroidal aromatase inhibitor has been broadly used to operate the sex ratio and its effects on gonadal development in Nile tilapia (Kwon et. al.,2000) (Kwon et. al.,2001 ) (Kwon et. al.,2002), common carp(Pandian, T. J. and Varadaraj, K., 1987), etc. Fadrozole inhibiting the aromatase enzyme by quickly joining to the heme of the cytochrome P450 subunit of the enzyme, resulting in a reducing of estrogen biosynthesis in all tissues that can result in an elevated level of androgen (by preventing the conversion of androgens to estrogens), thus leading sex reversal from genetic female to phenotypic male. In India, Das et. al., 2007 did series of experiment and he got $100 \%$ male population in $O$. mossambicus by administering $17 \alpha$ MT through rearing medium for 7 to 10 days old fry for a period of 11 to 19 days at dosage of 5 and $10 \mu \mathrm{g} / 1$ water. It is possible to manipulate the sex ratio by letrozole (a non-steroidal aromatase inhibitor) in the $O$. mossambicus by oral administration. This is first time done by using nanotechnology efficiently in the Nile Tilapia. Which showed increase the male population with lesser dose of nano-encapsulated Fadrozole (FDZ)-loaded PLGA nanoparticles drug as compared with naked control Fadrozole (FDZ) drug delivery.

\section{MATERIALS AND METHODS}

\section{Chemicals used}

Preparation of FDZ-loaded PLGA NPs: The nanoparticles loaded with Fadrozole were prepared by solvent displacement technique as per the reported meth- od (Mondal et al., 2008) with some alteration. Briefly, a solution of $150 \mathrm{mg}$ of PLGA (50:50) in $10 \mathrm{ml}$ of acetone taken into a Trsonssterile centrifuge tube conical bottom of $50 \mathrm{ml}$ capacity and did vortexing using vortex mixture. After that another Tarsons sterile Centrifuge Tube Conical Bottom of 50ml capacity containing $50 \mathrm{mg}$ of Fadrozole (drug polymer ratio 1:3) taken into the $20 \mathrm{ml}$ of acetone with vortexing using vortex mixture. This prepared vortex mixture of both chemicals added together in another sterile Centrifuge Tube Conical Bottom of $50 \mathrm{ml}$ capacity and vortex it for $5 \mathrm{~min}$. This newly prepared mixture of PLGA and Fadrozole was added at a constant flow rate $(0.2 \mathrm{ml} / \mathrm{min})$ to $1 \mathrm{lt}$. capacity beaker which contain $500 \mathrm{ml}$ an aqueous phase containing $1 \%(\mathrm{w} / \mathrm{v})$ poloxamer-188 at a under mechanical stirring at $10,000 \mathrm{rpm}$. The organic phase was evaporated at room temperature with constant stirring for $5 \mathrm{~h}$. Finally the nanoparticles were isolated by centrifugation at $17500 \mathrm{rpm} 4 \circ \mathrm{C}$ for $40 \mathrm{~min}$.

Characterization of nanoparticles: Measurement of size with zeta potential was carried out by using Horiba nano Partica SZ-100 series (Japan) which is based on dynamic light scattering (DLS) technique. Depending on the physical properties of the sample, the dynamic range of the equipment was $0.3 \mathrm{~nm}$ to $8 \mu \mathrm{m}$.

Analysis of the charge on the surface or zeta potential of particles is performed by injecting the sample into a disposable cell and a measurement of the Electrophoretic mobility. This calculates zeta potential. The zeta potential of the sample is most often used as an indicator of dispersion stability. Large magnitude zeta potential values indicate that an electrostatically stabilized suspension will remain stable. The surface morpholo-

\begin{tabular}{|c|c|c|c|}
\hline Chemical Name & Chemical Formula / Structure & Manufa-cturing Firm & Toxicity \\
\hline $\begin{array}{l}\text { Poly(D,L-lactide-co- } \\
\text { glycolide) lactide:glycolide } \\
(50: 50), \text { mol wt } 30,000 \text { - } \\
60,000,\end{array}$ & {$\left[\mathrm{CH}_{3}\right]_{x}[$} & SIGMA-ALDRICH & Nil \\
\hline $\begin{array}{l}\text { Fadrozole hydrochloride (4 } \\
-(5,6,7,8- \\
\text { Tetrahydroimidazo[1,5-a] } \\
\text { pyridin-5-yl)-benzonitrile) } \\
\geq 98 \% \text { (HPLC) }\end{array}$ & & SIGMA-ALDRICH & Nil \\
\hline $\begin{array}{l}\text { Poloxamer } 188 \\
\text { (Kolliphor }{ }^{\circledR} \text { P } 188\end{array}$ & $\mathrm{CH}_{3}$ & SIGMA-ALDRICH & Nil \\
\hline $\begin{array}{l}\text { Ethylene glycol } \\
\text { anhydrous, } 99.8 \%\end{array}$ & $\mathrm{HOCH}_{2} \mathrm{CH}_{2} \mathrm{OH}$ & SIGMA-ALDRICH & Nil \\
\hline $\begin{array}{l}\text { Other Chemicals and Sol- } \\
\text { vents (Analytical grade) }\end{array}$ & --- & Merck India & Nil \\
\hline
\end{tabular}

(Chemical Formula / Structure Source: Sigma Catalogue 2016-17) 
Harshavardhan D. Joshi et al. / J. Appl. \& Nat. Sci. 9 (4): 1921 -1925 (2017)

Table 1. Male, female and survival percentage of different treatments at different time interval.

\begin{tabular}{|c|c|c|c|c|c|c|c|c|c|}
\hline \multirow{2}{*}{$\begin{array}{l}\text { Treat- } \\
\text { ment }\end{array}$} & 10 days & 15 days & \multicolumn{7}{|l|}{30 days } \\
\hline & $\begin{array}{l}\text { Male } \\
(\%)\end{array}$ & $\begin{array}{l}\text { Female } \\
(\%)\end{array}$ & $\begin{array}{l}\text { Survival } \\
(\%)\end{array}$ & Male(\%) & $\begin{array}{l}\text { Female } \\
(\%)\end{array}$ & $\begin{array}{l}\text { Survival } \\
(\%)\end{array}$ & Male(\%) & $\begin{array}{l}\text { Female } \\
\text { (\%) }\end{array}$ & $\begin{array}{l}\text { Survival } \\
(\%)\end{array}$ \\
\hline $\mathrm{T} 1$ & $48.48^{\mathrm{a}} \pm 1.51$ & $51.51^{\mathrm{e}} \pm 1.51$ & $85.92 \pm 3.72$ & $47.15^{\mathrm{a}} \pm 0.51$ & $52.84^{\mathrm{e}} \pm 0.51$ & $94.28 \pm 1.64$ & $47.40^{\mathrm{a}} \pm 0.78$ & $52.59^{c} \pm 0.78$ & $96.66 \pm 5.84$ \\
\hline $\mathrm{T} 2$ & $65.87^{c} \pm 0.79$ & $34.12^{\mathrm{d}} \pm 0.79$ & $85.92 \pm 4.54$ & $70.05^{\mathrm{c}} \pm 0.77$ & $29.94^{\mathrm{c}} \pm 0.77$ & $92.38 \pm 2.43$ & $88.96^{\mathrm{b}} \pm 1.69$ & $11.03^{\mathrm{b}} \pm 1.69$ & $100.00 \pm 3.84$ \\
\hline $\mathrm{T} 3$ & $48.45^{\mathrm{a}} \pm 0.90$ & $51.54^{\mathrm{e}} \pm 0.90$ & $85.18 \pm 4.63$ & $47.25^{\mathrm{a}} \pm 0.54$ & $52.74^{\mathrm{e}} \pm 0.54$ & $94.28 \pm 0.12$ & $47.24^{\mathrm{a}} \pm 0.94$ & $52.75^{\mathrm{c}} \pm 0.94$ & $96.66 \pm 6.14$ \\
\hline $\mathrm{T} 4$ & $55.08^{\mathrm{b}} \pm 0.40$ & $44.91^{\mathrm{e}} \pm 0.40$ & $89.62 \pm 1.91$ & $58.37^{b} \pm 0.65$ & $41.62^{\mathrm{d}} \pm 0.65$ & $93.33 \pm 1.52$ & $89.31^{\mathrm{b}} \pm 1.97$ & $10.68^{\mathrm{b}} \pm 1.97$ & $98.88 \pm 4.01$ \\
\hline T5 & $78.39^{\mathrm{d}} \pm 1.42$ & $21.60^{\mathrm{c}} \pm 1.42$ & $87.40 \pm 4.14$ & $85.21^{\mathrm{d}} \pm 1.23$ & $14.78^{\mathrm{b}} \pm 1.23$ & $92.38 \pm 1.62$ & $95.92^{c} \pm 2.09$ & $4.08^{\mathrm{a}} \pm 2.09$ & $97.77 \pm 1.11$ \\
\hline T6 & $88.76^{\mathrm{e}} \pm 1.07$ & $11.23^{\mathrm{b}} \pm 1.07$ & $85.18 \pm 3.22$ & $95.53^{\mathrm{e}} \pm 0.89$ & $4.46^{\mathrm{a}} \pm 0.89$ & $93.33 \pm 1.44$ & $100.00^{\mathrm{a}}$ & $0.00^{\mathrm{a}}$ & $97.77 \pm 4.85$ \\
\hline $\mathrm{T} 7$ & $92.35^{\mathrm{f}} \pm 0.86$ & $7.64^{\mathrm{a}} \pm 0.86$ & $85.18 \pm 5.10$ & $97.76^{\mathrm{e}} \pm 1.12$ & $2.23^{\mathrm{a}} \pm 1.12$ & $92.38 \pm 1.62$ & $100.00^{\mathrm{a}}$ & $0.00^{\mathrm{a}}$ & $95.55 \pm 6.75$ \\
\hline$P$ value & $<0.001$ & $<0.001$ & 0.985 & $<0.001$ & $<0.001$ & 0.985 & $<0.001$ & $<0.001$ & 0.985 \\
\hline
\end{tabular}

Table 2. The particle size, zeta-potential and poly dispersive index a PLGA and FDZ-loaded PLGA NPs.

\begin{tabular}{llll}
\hline Nanoparticles & Particle size $(\mathbf{n m})$ & Zeta potential & $\begin{array}{c}\text { Poly dispersive index / } \\
\text { normal Standard Deviation }\end{array}$ \\
\hline PLGA & $136 \pm 74.7$ & $-18.20 \mathrm{mv}$ & 0.547 \\
FDZ- PLGA & $201.4 \pm 66.7$ & $-20.82 \mathrm{mv}$ & 0.331 \\
\hline
\end{tabular}

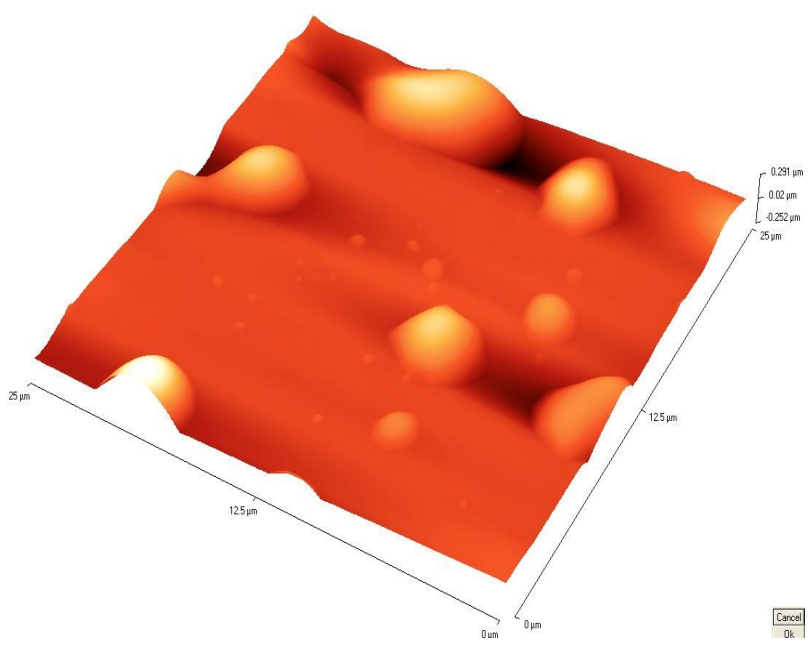

Fig. 1. Three-Dimension AFM image of FDZ-loaded PLGA. NPs.

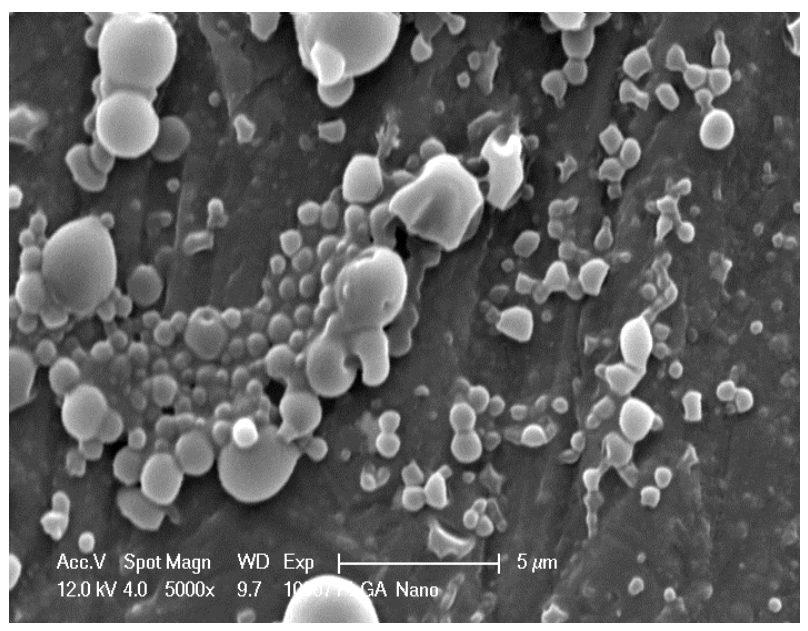

Fig. 2. SEM image of FDZ-loaded PLGA NPS. gy (roundnesss, smoothness and formation of aggregates) was studied by Atomic Force Microscopy and scanning electron microscope.

Preparation of diet: The treatment diet used in present study was the Firest Bite. Which is commercially available hatchling and fry feed procured from Hikari, Japan. About $100 \mathrm{~g}$ of feed was weighed and used for incorporation of PLGA conjugated Fedrazole.

Incorporation of FDZ-loaded PLGA NPs into fish feed: PLGA NPs conjugated FDZ were incorporated into the feed as follows: The appropriate amount of FDZ-loaded PLGA NPs i.e. 5, 25, 50 and $100 \mathrm{mg}$ (weighed accurately using an electrical balance) was dissolved in $50 \mathrm{ml}$ of $95 \%$ acetone. The required quantity of powdered feed was taken in an enamel tray and the FDZ-loaded PLGA NPs dissolved in acetone were sprayed uniformly using a chromatogram column sprayer. Preparation of negative control: The negative control diet was prepared in the same manner using only the solvent (acetone).

Preparation of positive control: The positive control diet was prepared in the same manner using only $100 \mathrm{mg}$ pure Fadrozole in the solvent (acetone).

Incorporation of PLGA NPs into fish feed: Incorporation of PLGA nanoparticles into the fish feed was accomplished as follows: The appropriate amount of PLGA nanoparticles that is $100 \mathrm{mg}$ (weighed accurately using an electrical balance) was dissolved in $50 \mathrm{ml}$ of $95 \%$ acetone. The 10 gm of powdered feed was taken in an enamel tray and the PLGA nanoparticles dissolved acetone was sprayed uniformly using a chromatogram column sprayer.

Development of brood-stock: The brooders were reared in cemented tank $(6 \times 4 \times 3 \mathrm{ft})$ until they are matured. The gravid female and male tilapia were released in aquaria $(2 \times 1 \times 1 \mathrm{ft})$ in the ratio of $2: 1(\mathrm{~F}: \mathrm{M})$. 
The fish were fed twice daily on artificial diet as well as mosquito larvae, tubifex, bloodworm, earth worm and zooplankton at libido.

Seed production of tilapia: The female and male brooders were placed in a big aquarium with muddy bottom to released eggs and sperm. After fertilization the female takes all eggs into her mouth for the incubation upto free swim. The resultant fry were used for experimentation. The aquaria were aerated using an air blower.

\section{FDZ-loaded PLGA NPs administration to fry}

Trial 1: This trial was conducted for 10 days. The twoday-old spawn (initial weight $6.13 \mathrm{mg}$ ) were divided into 7 groups of 35 each and designated as $T_{1}, T_{2}, T_{3}, T_{4}, T_{5}, T_{6}$ and $\mathrm{T}_{7}$ for negative control, positive control, PLGA nanoparticle (100 ppm) and 5, 25, 50 and 100ppm of FDZloaded PLGA NPs respectively. Fishes were fed daily (100\% body weight) for the first ten days.

Trial 2: This trial was conducted for 15 days. The oneday-old spawn (initial weight $3.98 \mathrm{mg}$ ) were divided into 7 groups of 30 each and designated as $T_{1}, T_{2}, T_{3}, T_{4}, T_{5}, T_{6}$ and $\mathrm{T}_{7}$ for negative control, positive control, PLGA nanoparticle (100 ppm) and 5, 25, 50 and 100ppm of FDZloaded PLGA NPs respectively. They were fed daily@ $100 \%$ body weight for the first ten day and $75 \%$ for the next 5 days ( $11^{\text {th }}$ and $15^{\text {th }}$ day).

Trial 3: This trial was conducted for 30 days. The twoday-old spawn (initial weight $4.0 \mathrm{mg}$ ) were divided into 7 groups of 45 each and designated as $\mathrm{T}_{1}, \mathrm{~T}_{2}, \mathrm{~T}_{3}, \mathrm{~T}_{4}, \mathrm{~T}_{5}, \mathrm{~T}_{6}$ and $T_{7}$ for negative control, positive control (100ppm pure Fadrozole without nanoparticles), PLGA nanoparticle (100 ppm) and 5, 25, 50 and 100ppm of FDZ-loaded PLGA NPs respectively. They were provided feed daily (a) 100\% body weight for the first ten days, 75\% for the next 15 days and $50 \%$ for the last 5 days.

Evaluation of all treatments: On termination of the experiments, all the surviving fish were harvested, counted and measured for weight and length and sexed by simple light macroscopic inspection. The phenotypic sex of the treated and control fish was determined with the help of secondary sexual characters, such as the shape of the belly, presence of number of gonopore.

Statistical analysis: Data on percentage of male produced in each treatment was analyzed using one way ANOVA to test the significant difference of mean values and standard error using SPSS 18 software.

\section{RESULTS AND DISCUSSION}

Physiochemical characterization of nanoparticles: In the present study, the Fadrozole loaded PLGA Nanoparticles (FDZ-PLGA NPs) were prepared by using solvent displacement technique as per the reported method with some alteration had particle size be in the range of $60 \pm 66.7 \mathrm{~nm}$ to $560 \pm 66.7 \mathrm{~nm}$ with an average size of $201.4 \pm 66.7 \mathrm{~nm}$ and zeta potency about $-20.82 \mathrm{mV}$ (Table 2, Fig. 1, 2). Three trials were made to test the efficiency of FDZ-PLGA NPs to induce the masculinization in research animal. FDZ-loaded PLGA NPs were prepared by solvent displacement technique. This yielded spherical powder particles with diameter of LTZ-loaded PLGA nanoparticles $15-100 \mathrm{~nm}$. The loading efficiency as well as drug entrapment efficiency of LTZ-loaded PLGA NPs was $77.44 \pm 0.24$ and $43.03 \pm 2.20 \%$, respectively. The zeta potential values of LTZ-loaded PLGA NPs were found to be negative, -12 to $-19.50 \mathrm{mV}$ (Mondal et al., 2010).

The dexamethezone in PLGA nanoparticles was developed for treating disease like rheumatoid, (Park et al., 2012) the average size was $50 \mathrm{~nm}$ with drug loading efficiency was $56.18 \pm 5.39 \%$.

This is justified that the developed nanoparticle size occurred in between the reported nanoparticles size which is cited above and particles are morphologically spherical and compact and shown more stable.

Male and female percentage and survival rate: Generally, Fadrozole shows effects on sex ratio, increases in percentage of male production with directly proportional to the dose of FDZ-loaded PLGA NPs. (Tables 1). The survival percentage of fry (Tables 1 ) observed that there was no mortality observed in the FDZ-loaded PLGA NPs fed experimental fishes. It is indicated that the use of FDZ -loaded PLGA nanoparticles in Tilapia (Oreochromis niloticus) is reasonably safe for masculinization of fish.

The male percentage was $92.35 \pm 0.86$ for $\mathrm{T} 7$ at 10 days, $97.76 \pm 1.12$ for $\mathrm{T} 7$ at 15 days and $100 \%$ for both T6 (50ppm) and T7 (100 ppm) at 30 days, Lowest male percentage was found at T4 treatment of all groups. It was reported that the male percentage of treatment T2 (naked fadrozole at $100 \mathrm{ppm}$ ) and Treatment T4 (FDZPLGA NPs at 5 ppm) were $88.96 \%$ and $89.31 \%$ respectively for 30 days treatment (Trial 3). These finding shows that FDZ in nano forms can reduce $90 \%$ of prescribed dose of fadrozole for masculinization of commercial fish like tilapia.

It was observed that the percentage of male production in treatment T4 during 10 and 30 days' time interval was increased from 55.08 to $89.31 \%$. It is 'therefore' administrated FDZ- PLGA NPs at low dose ( 5 ppm per $\mathrm{kg}$ ) for prolong period, presented significant sex reversal and also helped to reduce cost of drug and its adverse impact on Oreochromis niloticus. The sex ratio was significantly $(\mathrm{P}<0.001)$ altered in the FDZ-PLGA NPs treated groups in compare to control groups in all treatments with respect to trials and doses except T3 which has PLGA nanoparticle without Fadrozole (drug) and check the impact of nanoparticle on experimental fishes (Table 1). Among LTZ-loaded PLGA nanoparticles treated groups, the lowest percentage of males $(82.63 \%)$ was observed in $5 \mathrm{ppm}$ group; while the highest percentage of males $(100 \%)$ was found at 50 and $100 \mathrm{ppm}$ when fed for 30 days. Das (2007) observed that the manipulation of the sex ratio in $O$. mossambicus was possible by oral administration of letrozole (a non-steroidal aromatase inhibitor). Dietary administration of letrozole (100 and $200 \mathrm{ppm}$ ) was produced $92-100 \%$ males when fed to 5-6 day-old-fry for 30 days. 
In the recent past decade the Fadrozole a non-steroidal aromatase inhibitor has been broadly used to operate the sex ratio and its effects on gonadal development in Nile tilapia (Kwon et al., 2000 ) (Kwon et al., 2001 ) (Kwon et al., 2002), common carp (Pandian, T.J and Varadaraj, K., 1987), etc. Fadrozole inhibiting the aromatase enzyme by quickly joining to the heme of the cytochrome P450 subunit of the enzyme, resulting in a reducing of estrogen biosynthesis in all tissues that can result in an elevated level of androgen (by preventing the conversion of androgens to estrogens), thus leading sex reversal from genetic female to phenotypic male. In India, 100\% male population in $O$. mossambicus by administering $17 \alpha \mathrm{MT}$ through rearing medium to 7 or 10 days old fry for a period of 11 19 days at dosage of 5 and $10 \mu \mathrm{g} / 1$ water. (Das et al., 2007) it is possible to manipulate the sex ratio by letrozole (a non-steroidal aromatase inhibitor) in the $O$. mossambicus by oral administration. It is observed that LTZloaded PLGA nanoparticles treated groups, the lowest percentage of males $(82.63 \%)$ was observed in $5 \mathrm{ppm}$ group; while the highest percentage of males (100\%) was found at 50 and $100 \mathrm{ppm}$ when fed for 30 days (Joshi et al., 2015). The results showed an increase in the proportion of males with dosage and duration of treatment and cited reported works supported the present work.

\section{Conclusion}

The results stated developed a new Fadrozole (FDZ)loaded PLGA nanoparticles for effective delivery of the masculinization drug. The use of nanoparticles significantly showed the effect on masculinization as compared with naked drug delivery. This type of Nano encapsulated drug can be prepared easily and economically by using standard protocol at farm level lab by using only magnetic stirrer with basic lab equipment.

\section{ACKNOWLEDGEMENTS}

We are thankful to the CIFE, Mumbai and ICAR, New Delhi for financial support.

\section{REFERENCES}

Brannon-Peppas, L. (1995). Recent advances on the use of biodegradable micro particles and nanoparticles in controlled drug delivery. Int. J. Pharm. 116: 1-9.

Brigger, I., Dubernet, C., Couvreur, P. (2002). Nanoparticles in cancer therapy and diagnosis. Adv. Drug Deliv. Rev. 54: 631-651.

Chiang E.F.L., Yan Y.L., Guiguen Y., Postlethwait J. and Chung B. (2001). Two Cyp19 (P450 Aromatase) Genes on Duplicated Zebrafish Chromosomes Are Expressed in Ovary or Brain. Mol. Biol. Evol. 18 (4): 542-550.

Das,T., Chattopadhyay,R., Ghosh,S., Goswami, S., Chattopadhyay D., Chakravarty, B. and Kabir,S. N. (2007). Role of an estrogen-upregulated $64.0-\mathrm{kDa}$ uterine fluid glycoprotein in improving fertility in women. American Society for Reproductive Medicine, Published by Elsevier Inc. 87 (2): 343-350.

Hughes, G.A., (2005). Nanostructure mediated drug delivery.
Nanomedicine 1: 22-30.

Komatsu, T., Nakamura, S., Nakamura, M. (2006). Masculinization of female golden rabbitfish Siganus guttatus using an aromatase inhibitor treatment during sex differentiation. Comp. Biochem. Physiol. C. Toxicol. Pharmacol. 143: 402 $-409$

Khawa H. L., Ponzonia R.W., Dantingb M. J. C. (2008). Estimation of genetic change in the GIFT strain of Nile tilapia (Oreochromis niloticus) by comparing contemporary progeny produced by males born in 1991 or in 2003.Aquaculture 275, 64-69.

Kwon, J.Y., Hoghponah, H., Kagson-Hurtodo, L.M., MC Andrew, B.J. and Penman, D.J. (2000). Masculinization of genetic female Nile tilapia (O.nioticlus) by dietary administration of an aromatase inhibitor during sexual differentiation. J.Exp.Zool., 287:46-53

Kwon, J.Y., MC Andrew, B.J. and Penman, D.J. (2001). Cloning of brain aromatase gene and expression of brain and ovarian aromatase gene during sexual differentiation in genetic male and female Nile tilapia (O.niloticus). Mol.Reprod. Dev., 59:359-370.

Kwon, J.Y., MC Andrew, B.J. and Penman, D.J. (2002). Treatment with an aromatase inhibitors suppresses high temperature feminization of genetic male (YY) Nile tilapia. J.Fish.Biol. 60:625-636.

Mondal, N., PAL, T. K.,Ghosal S. K. (2008). Development, physical characterization, micromeritics and in vitro release kinetics of letrozole loaded biodegradable nanoparticles. Pharmazie 63: 361-365.

Mondal, N., Halder, K. K., Kamila, M. M., Debnath, M. C., Pala, T. K., Ghosal, S.K., Sarkar, B. R. and Ganguly, S. (2010). Preparation, characterization, and biodistribution of letrozole loaded PLGA nanoparticles in Ehrlich Ascites tumor bearing mice. International Journal of Pharmaceutics. 397: 194-200.

Otilia M. K., Rubinstein I., Onyuksel H. (2005).Role of nanotechnology in targeted drug delivery and imaging: a concise review. Nanomedicine 1: 193-212.

Park, J. S., Yang, H. N., Jeon, S. Y., Woo, D. J., Kim, M. S. and Park, K. H. (2012). The use of anti-COX2 siRNA coated onto PLGA nanoparticles loading dexamethasone in the treatment of rheumatoid arthritis. Biomaterials. 33: 86008612.

Pandian, T.J. and Varadaraj, K. (1987). Techniques to regulate sex ratio and breeding in tilapia. Curr. Sci., 56: $337-$ 343.

Piferrer, F. (2001). Endocrine sex control strategies for the feminization of teleost fish. Aquaculture., 197: 229281.

Tchoudakova A. and Callard G. V. (2011). Identification of Multiple CYP19 Genes Encoding Different Cytochrome P450 Aromatase Isozymes in Brain and Ovary. Endocrinology. 139: 2179-2189.

NABARD (2016). The National Bank for Agricultural and Rural Development (NABARD) retrieved from https:// www.nabard.org/search-result.aspx?S=aquaculture

Tzchori, I., Zak, T., and Saches, O. (2004). Masculinization of genetic females of the common carp (Cyprinus carpio) by dietary administration of an aromatase inhibitor. The.Israel. J.Aqua, 56(4): 239-246.

Vauthier, C., Dubernet, C., Chauvierre, C., Brigger, I., Couvreur, P. (2003). Drug delivery to resistant tumors: the potential of poly (alkyl cyanoacrylate) nanoparticles. J. Control. Release 93:151-160. 